\title{
Vestibular migraine: diagnosis challenges and need for targeted treatment
}

\author{
Migrânea vestibular: desafios diagnósticos e a necessidade de tratamentos específicos \\ Felipe Barbosa, Thaís Rodrigues Villa
}

\begin{abstract}
Approximately $1 \%$ of the general population suffers from vestibular migraine. Despite the recently published diagnostic criteria, it is still underdiagnosed condition. The exact neural mechanisms of vestibular migraine are still unclear, but the variability of symptoms and clinical findings both during and between attacks suggests an important interaction between trigeminal and vestibular systems. Vestibular migraine often begins several years after typical migraine and has a variable clinical presentation. In vestibular migraine patients, the neurological and neurotological examination is mostly normal and the diagnosis will be based in the patient clinical history. Treatment trials that specialize on vestibular migraine are scarce and therapeutic recommendations are based on migraine guidelines. Controlled studies on the efficacy of pharmacologic interventions in the treatment of vestibular migraine should be performed.
\end{abstract}

Keywords: migraine; vestibular migraine; dizziness; vertigo.

RESUMO

Cerca de 1\% da população apresentam o diagnóstico de migrânea vestibular. Apesar dos critérios diagnósticos terem sido publicados recentemente, ainda é uma condição subdiagnosticada. Os mecanismos neurais exatos da migrânea vestibular ainda não estão claros, mas a variabilidade dos sintomas e achados clínicos durante e entre os ataques sugere uma interação importante entre os sistemas trigeminal e vestibular. A migrânea vestibular geralmente começa alguns anos após a migrânea típica e tem apresentação clínica variável. Em pacientes com migrânea vestibular, o exame neurológico e otoneurológico são geralmente normais e o diagnóstico é baseado na história clínica do paciente. Estudos sobre tratamento da migrânea vestibular são escassos e recomendações terapêuticas são baseadas em diretrizes do tratamento da migrânea. Estudos controlados sobre a eficácia das intervenções farmacológicas para o tratamento da migrânea vestibular devem ser realizados.

Palavras-chave: migrânea; migrânea vestibular; tontura; vertigem.

Dizziness is one of the most common complaints in clinical practice, affecting $20-30 \%$ of the general population ${ }^{1}$ and is often reported by patients with migraine ${ }^{2}$. The prevalence of migraine is higher in patients with dizziness ${ }^{2}$, and benign recurrent vertigo is the most prevalent type of dizziness in this population $^{3,4}$. The relationship between dizziness and migraine was first described by the ancient Greek physician Aretaeus of Cappadocia in $131 \mathrm{BC}^{5}$. In 1873, Edward Liveing observed an association between migraine and dizziness in some of his patients $^{6}$. However, detailed observation of this association was initiated only in the last 30 years. Since the first studies of Kayan et al. about the vestibular manifestations of migraine ${ }^{7}$ the number of articles addressing the relationship between vertigo and migraine has grown exponentially in the last 25 years $^{8,9}$. Different terms have been used to designate the relationship of vertigo and migraine including migraine-associated vertigo, migraine-associated dizziness, migraine-related vestibulopathy, migrainous vertigo, benign recurrent vertigo. More recently the term vestibular migraine (VM) was defended as a condition that covers the vestibular manifestations that may occur in migraine, avoiding confusion with nonvestibular dizziness that may also be associated with migraine ${ }^{10}$.

\section{EPIDEMIOLOGY}

Despite vestibular migraine is one of the most common diagnoses in dizziness units (the second most common cause of recurrent vertigo after benign paroxysmal positional vertigo (BPPV)) accounting for 6-9\% of all diagnoses, it is still underdiagnosed ${ }^{2,9}$. In a study conducted by a specialized clinic in Switzerland, dizziness was diagnosed as vestibular 
migraine in $20.2 \%$ of patients, although VM was previously suspected by the requesting physicians in only $1.8 \%$. The diagnosis of "uncertain dizziness" accounted for almost $60 \%$ of patients ${ }^{11}$. In another study in Germany, with 33 patients, two-thirds of patients diagnosed with VM had consulted a doctor because of vertigo, but only $20 \%$ were diagnosed with VM. The remaining patients were diagnosed with other diseases such as anemia, diabetes, hypovolemia ${ }^{12}$. Vestibular migraine has a year prevalence of $0.89 \%$ and represents about $10 \%$ of patients treated for either migraine and dizziness ${ }^{13}$. Hsu and colleagues reported a year prevalence of vestibular migraine in women aged $40-54$ years of $5 \%{ }^{14}$. Forty percent of patients with vestibular migraine reported missing work because of their symptoms, showing the impact of the disease on daily life ${ }^{12}$. Vestibular migraine can occur at any age, but the average age of onset of dizziness in migraine is about 40, and a first attack late age in 72 years has been reported. It has a female predominance, the female and male ratio of $5: 1^{2,12,15}$. In older patients, particularly post-menopausal women, typical migraine attacks are sometimes replaced by isolated episodes of vertigo, dizziness or transient feeling of imbalance ${ }^{16}$. In a population-based study, the prevalence of recurrent vertigo probably related to migraine was estimated at $2.8 \%$ in children with $6-12$ years ${ }^{17}$. Vestibular migraine is diagnosed more often in children than adults (35\% vs $6 \%)^{8}$. The most common cause of vertigo in children is benign paroxysmal vertigo, which has a strong association with a family history of migraine and may predict the development of typical migraine ${ }^{18}$.

\section{Pathophysiology}

The exact neural mechanisms of vestibular migraine are still unclear. The variability of symptoms and clinical findings both during and between attacks suggests that migraine interacts with the vestibular system at various levels ${ }^{19}$.

The vestibular nuclei receive noradrenergic inputs from the locus ceruleus and serotoninergic inputs from the dorsal raphe nucleus ${ }^{20,21}$. Therefore, activation of these nuclei during migraine attacks may give rise to vestibular symptoms. Since the caudalis trigeminal nucleus also has reciprocal connections with the vestibular nuclei, and neurogenic inflammation of the trigeminal system is believed to be a mechanism of migraine, trigeminal activation may provoke vestibular symptoms during migraine attacks. Trigeminal activation by painful electrical stimulation of the forehead produced spontaneous nystagmus in migraine patients, but not in controls, indicating that those with migraine have a lowered threshold for crosstalk between these neighboring brainstem structures ${ }^{22}$. Shin and colleagues studied 2 patients with vestibular migraine who underwent FDG-PET images. During attacks of vestibular migraine, the increased metabolism of the temporo-parieto-insular areas and bilateral thalami indicated activation of the vestibulothalamo-vestibulocortical pathway, and the decreased metabolism in the occipital cortex may represent reciprocal inhibition between the visual and vestibular systems ${ }^{23}$. Another image study comparing vestibular migraine patients with migraine without aura (MwoA) and healthy controls (HC) showed that patients with VM showed a significantly increased left mediodorsal thalamic activation in response to an ipsilateral vestibular stimulation, relative to both $\mathrm{HC}$ and patients with MwoA. Furthermore, the magnitude of left thalamic activation was uniquely correlated with frequency of migraine attacks in patients with $\mathrm{VM}^{24}$. The role of mediodorsal thalamus in VM pathophysiology could reflect the involvement of a dysfunctional vestibulo-thalamocortical network, which overlaps with the migraine circuit $^{19}$.

Cortical spreading depression (CSD) in both multisensory vestibular areas of the cortex and brainstem was used as an explanation for 'aura'-like dizziness/vertigo attacks with consecutive headache. However, an isolated CSD, which is limited to the brain stem without causing any other symptoms, is not very likely ${ }^{25}$.

Some authors suggested a genetic inheritance. A linkage analysis in a four-generation family with 10 affected individuals mapped the locus for vestibular migraine to chromosome $5 \mathrm{q} 35^{26}$. In a larger study, familial vestibular migraine was found to be genetically heterogeneous with a subgroup linking to chromosome $22 \mathrm{q} 12^{27}$.

The most current pathophysiologic model of vestibular migraine is summarized in Figure.

\section{Diagnostic criteria}

The International Headache Society (IHS) and the Bárány-Society (International Society for Neuro-Otology) created a consensus document with diagnostic criteria for vestibular migraine, which was added in the appendix of the new ICHD-3 beta version of the International Headache Classification $^{28}$ (Table 1).

\section{Clinical presentation}

Vestibular migraine often begins several years after typical migraine ${ }^{2,15}$. In a previous study, migraine manifested before $\mathrm{VM}$ in $74 \%$ of participants and in more than half of these (52\%) migraine was preceded by VM by more than 5 years, and in $26 \%$ even by more than 10 years. The vast majority of patients (85\%) had experienced both VM and migraine during the last 12 months $^{12}$. Vestibular migraine is more common in patients without aura than in patients with aura ${ }^{29}$. The most frequent vestibular symptoms associated with migraine are spontaneous vertigo in $67 \%$ followed by positional vertigo in $24 \%$ of these patients ${ }^{12}$. Other commonly described symptoms are: imbalance, head motion intolerance, visual vertigo and non-vertiginous dizziness such as lightheadness or "boat like" rocking ${ }^{13,30}$.

The duration of attacks can vary from a few seconds (10\% of patients) to some minutes (30\% of patients), some 


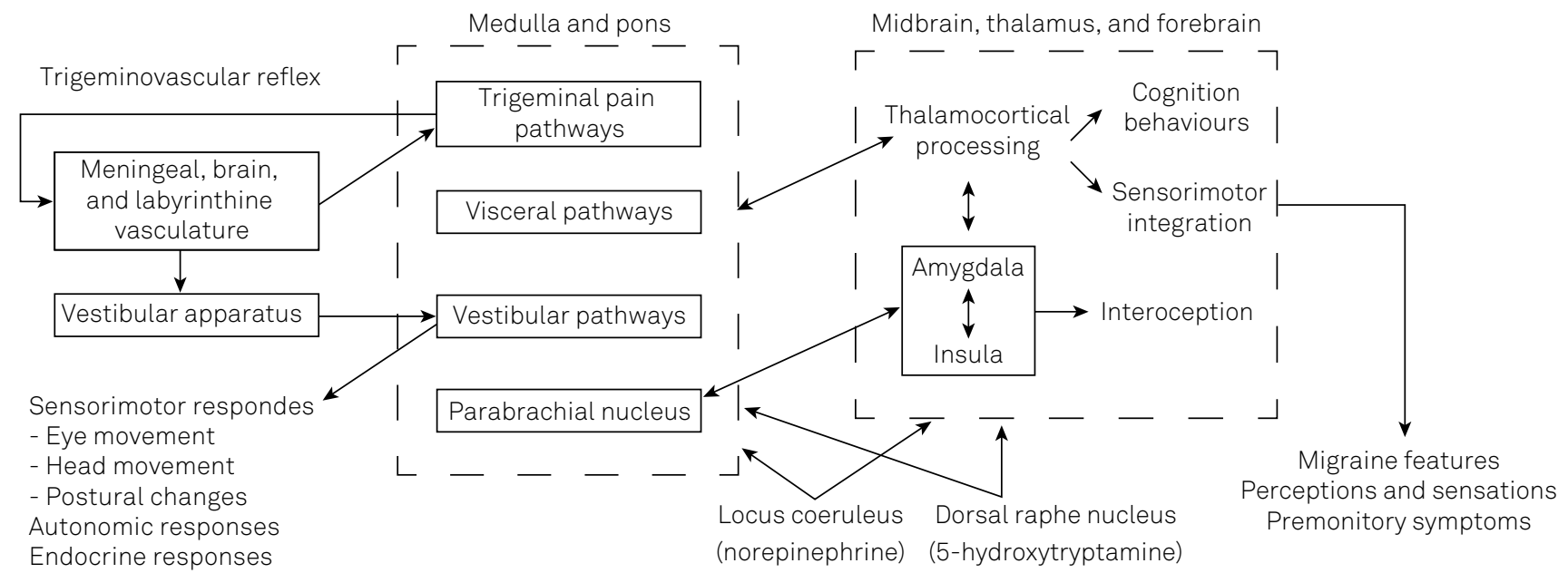

Figure. Summary of patophysiologic model of vestibular migraine.

hours (30\% of patients) and even up to a few days (30\% of patients $)^{25}$. Only $10-30 \%$ of patients described a typical vestibular aura. Vestibular symptoms can occur before, during or after the migraine attack and in $30 \%$ of the patients the two symptoms never occurred together ${ }^{2,31}$. Some patients reported vertigo as the most disabling symptom and only report a slight felling of pressure in the head replacing a typical migraine headache ${ }^{32,33}$.

Auditory symptoms, including hearing loss, tinnitus, and aural pressure have been reported in up to $38 \%$ patients with vestibular migraine. Hearing loss is usually mild and transient, without or with only minor progression in the course of the disease $\mathrm{e}^{2,34,35}$.

Radtke et al. reassessed 61 patients with definitive VM according to validated diagnostic criteria after a follow-up time of 9 years and their findings are shown on Table $2^{36}$.

Episodes of vestibular migraine can be brought about by the same triggers as those for migraine headache, including menstruation, irregular sleep, stress, physical exertion, dehydration, food and drinks, and intense sensory stimulation, mostly movement ${ }^{29}$.

In most patients, the neurologic and otologic examination is normal during the interictal phase ${ }^{32}$. About 10 to $30 \%$ of patients with vestibular migraine have unilateral hypoexcitability to caloric stimulation and $10 \%$ have directional preponderance of nystagmus responses. Such findings, however, are not specific for vestibular migraine, because they can be found also in migraine patients without vestibular symptoms and in many other vestibular syndromes ${ }^{37}$. In one study, patients with vestibular migraine became nauseous after caloric testing four times more often than migraine patients and patients with other vestibular disorders $^{38}$. A neuro-otologic study of 20 patients during the acute phase of vestibular migraine showed pathological nystagmus in 14 patients, mostly central spontaneous or positional nystagmus. Three patients had a peripheral spontaneous nystagmus and a unilateral deficit of the horizontal

Table 1. Vestibular migraine: diagnostic criteria.

A. At least five episodes fulfilling criteria $C$ and $D$.

B. A current or past history of 1.1 Migraine without aura or 1.2 Migraine with aura.

C. Vestibular symptoms of moderate or severe intensity, lasting between 5 minutes and 72 hours.

D. At least $50 \%$ of episodes are associated with at least one of the following three migrainous features:

1. headache with at least two of the following four characteristics:

a) unilateral location;

b) pulsating quality;

c) moderate or severe intensity;

d) aggravation by routine physical activity.

2. photophobia and phonophobia;

3. visual aura.

E. Not better accounted for by another ICHD-3 diagnosis or by another vestibular disorder.

ICHD-3: International Classification of Headach Disorders 3rd edition (beta version). 


\begin{tabular}{|c|c|c|}
\hline & Initial presentation (\%) & Follow up (\%) \\
\hline \multicolumn{3}{|l|}{ Type of vertigo } \\
\hline Spontaneous & 85 & 95 \\
\hline Spinning & 75 & 82 \\
\hline Positional & 39 & 80 \\
\hline Head-Motion-Induced & 61 & 84 \\
\hline Unsteadiness & 66 & 90 \\
\hline \multicolumn{3}{|l|}{ Duration of vertigo attacks } \\
\hline$<1 \min$ & 31 & 75 \\
\hline $1-5 \min$ & 30 & 56 \\
\hline $5-60 \mathrm{~min}$ & 34 & 64 \\
\hline$<24 h$ & 49 & 74 \\
\hline$>24 h$ & 52 & 69 \\
\hline \multicolumn{3}{|c|}{ Cochlear symptoms during vertigo spells } \\
\hline Tinnitus & 10 & 33 \\
\hline Aural fullness & 13 & 26 \\
\hline Hearing loss & 12 & 26 \\
\hline \multicolumn{3}{|c|}{ Migraine symptoms during vertigo attacks } \\
\hline Headache & 75 & 90 \\
\hline Photophobia & 59 & 80 \\
\hline Phonophobia & 54 & 77 \\
\hline Aura & 18 & 44 \\
\hline
\end{tabular}

vestibulo-ocular reflex. Imbalance was observed in all patients except one $\mathrm{e}^{39}$. Since there are no specific abnormalities in vestibular migraine, in general practice the diagnosis will be based in the patient clinical history.

\section{Differential diagnosis}

The main differential diagnosis of VM is Ménière's disease (MD). An association between MD and migraine was already suggested by Prosper Ménière himself in $1861^{40}$. Some studies have ratified a higher prevalence of migraine in patients with $\mathrm{MD}^{41,42}$, almost $30 \%$ of patients with Ménière syndrome may also have $\mathrm{VM}^{41}$. The overlap or coexistence of both diseases may make the patient's diagnosis difficult and the most reliable distinguishing feature is the low-frequency hearing loss in $\mathrm{MD}^{42}$. In general, MD distinguished from vestibular migraine by symptoms of ear fullness or pain preceding the attack or at attack onset, and accompanying tinnitus and/or hearing loss during the episode. These symptoms are not very prominent in vestibular migraine $e^{41,42}$.

Endolymphatic hydrops is the primary pathological entity seen in Ménière's disease ${ }^{43}$. Recent progress has made it possible to reliably visualize endolymphatic hydrops in living humans by employing a Locally Enhanced Inner ear MRI technique. Gurkov et al. investigated the occurrence of endolymphatic hydrops (EH) in patients with VM and auditory symptoms. Nineteen patients with definite or probable VM and auditory symptoms were examined by locally enhanced inner ear MR imaging. Of the 19 included patients, four patients $(21 \%)$ demonstrated evidence of cochlear and vestibular endolymphatic hydrops ${ }^{44}$.
In contrast, Nakada et al. investigated endolymphatic hydrops in seven patients with definitive VM and 7 patients with MD. EH was not found in VM patients but all patients with MD showed significant $\mathrm{EH}^{45}$.

$\mathrm{BPPV}$ is the most common cause of recurrent vertigo ${ }^{46}$. Episodic vertigo related to migraine occurs several times per year or month with a duration of some hours up to few days, whereas BPPV leads to episodes of short lasting vertigo typically lasting weeks to months without therapy ${ }^{47}$. During acute attacks of vertigo, the analysis of the positional nystagmus usually permits differentiation of positional $\mathrm{VM}$ from $\mathrm{BPPV}^{47}$.

Transient ischemia within the vertebrobasilar system is a common cause of episodic vertigo in older people. It is abrupt in onset, usually lasts several minutes, and is frequently associated with nausea

and vomiting ${ }^{48}$. Baloh studied 42 patients with vertigo in a neurotology service with the diagnosis of vertebrobasilar insufficiency and found that $62 \%$ had at least one episode of isolated vertigo and in 19\% the transient ischemic attack began with an isolated episode of vertigo ${ }^{49}$. Therefore, it is reasonable to investigate older patients with sudden onset of unilateral deafness and vertigo, particularly if there is a prior history of TIA, stroke, or known atherosclerotic vascular disease.

Basilar migraine requires at least two aura symptoms, which are assignable to the vertebrobasilar territory, lasting between 5 and 60 minutes and followed by a typical migraine headache ${ }^{25}$. Less than $10 \%$ of the patients with VM meet the criteria for basilar type migraine ${ }^{2}$. 


\section{Treatment}

Current VM treatment recommendations are most based on expert opinions rather than on solid data from randomized controlled trials. Most therapeutic approaches are based on case reports, retrospective cohort studies and open labels trials. In general, the scientific literature suggests that drugs efficacious for prophylaxis of migraine are also appropriate for prophylaxis of vestibular migraine ${ }^{49}$.

Neuhauser and colleagues suggested a benefit of zolmitriptan $2.5 \mathrm{mg}$ in $38 \%$ of patients with vestibular migraine whereas in the placebo group a positive effect was seen in $22 \%$. Unfortunately, the study had some limitations such as the large interval of confidence and the small number of patients recruited with only 17 reported attacks ${ }^{50}$.

In another study, 48 patients with VM diagnose received flunarizine $10 \mathrm{mg}$ daily along with betahistine and paracetamol during the migraine episodes and compared to the control group who received only the symptomatic treatment during the episodes. The frequency of vertiginous episodes showed a significant difference between the two groups, although the headache frequency and intensity did not improve in a significant degree ${ }^{51}$.

One retrospective single center open label investigation compared the effect of cinnarizine on VM and migraine with brainstem aura patients. Cinnarizine reduced the headache variables ( frequency, duration and intensity) in both types of migraine with greater outcomes in the vestibular migraine group. Vertigo was also decreased in both groups with significant reduction in the VM group in the first month ${ }^{52}$.

One retrospective, open-label study investigated the efficacy of $100 \mathrm{mg}$ lamotrigine in 19 patients (6 male, 13 female) with vestibular migraine over $3-4$ months. The average vertigo frequency per month was reduced from 18.1 to 5.4 , headache frequency dropped from 8.7 to 4.4 , but did not reach statistical significance. Therefore, lamotrigine appears to mainly act on vestibular symptoms and only to a lesser extent on headaches ${ }^{53}$.

A large retrospective cohort compared $100 \mathrm{VM}$ patients with and without prophylactic migraine treatment. All patients on prophylactic treatment showed a decrease of duration, intensity, and frequency of episodic vertigo as well as its associated features $(\mathrm{p}<0.01)$. Medications used were beta-blocker, 49 patients, metoprolol (median dose $150 \mathrm{mg}$ ) or propranolol (median dose $160 \mathrm{mg}$ ), valproic acid, 6 patients (median dose $600 \mathrm{mg}$ ), topiramate, 6 patients (median dose $50 \mathrm{mg}$ ), butterbur extract, 4 patients (median dose $50 \mathrm{mg}$ ), lamotrigine, 3 patients (median dose $75 \mathrm{mg}$ ), amitriptyline 2 patients (75 to $100 \mathrm{mg}$ ), flunarizine, 1 patient ( $5 \mathrm{mg}$ ), and magnesium 3 patients (median dose $400 \mathrm{mg}$ ). The group without prophylactic therapy showed a reduction of vertigo intensity only ${ }^{54}$. An ongoing trial will test the efficacy of metoprolol in vestibular migraine (Prophylactic treatment of vestibular migraine with metoprolol - PROVEMIG trial) $)^{55}$.

Behavioral modifications can be tried. One retrospective study showed that $14 \%$ of 38 patients enrolled reported an improvement in symptoms after caffeine cessation ${ }^{56}$.

Vestibular rehabilitation exercises were described to be beneficial in patients with vestibular migraine in addition to medical treatment or as stand-alone treatment option ${ }^{57}$. Improvement in physical performance measures and self-perceived abilities after a 4-month vestibular physical therapy was observed in 14 patients with the diagnosis of migraine related vertigo $^{58}$. In another cohort study, patients with vestibular disorders with or without a history of migraine demonstrated improvements after nine weeks in both subjective and objective measures of balance after 15 minutes daily physical therapy ${ }^{59}$.

\section{Clinical implications}

Vestibular migraine is quite prevalent but still underdiagnosed, and the impact on daily life activities and well-being is considerable. Treatment is not well established and therapeutic recommendations are based on migraine guidelin. The need of specific treatment is urgent. The migraine patient should be asked about vestibular symptoms by routine and controlled studies on the efficacy of pharmacologic interventions in the treatment of vestibular migraine should be performed.

\section{References}

1. Yardley L, Owen N, Nazareth I, Luxon L. Prevalence and presentation of dizziness in a general practice community sample of working age people. Br J Gen Pract. 1998;48(429):1131-5.

2. Neuhauser H, Leopold M, Brevern M, Arnold G, Lempert T. The interrelations of migraine, vertigo, and migrainous vertigo. Neurology. 2001;56(4):436-41. doi:10.1212/WNL.56.4.436

3. Lee H, Sohn SI, Jung DK, Cho YW, Lim JG, Yi SD et al. Migraine and isolated recurrent vertigo of unknown cause. Neurol Res. 2002;24(7):663-5. doi:10.1179/016164102101200726

4. Cha YH, Lee H, Santell LS, Baloh RW. Association of benign recurrent vertigo and migraine in 208 patients. Cephalalgia. 2009;29(5):550-5. doi:10.1111/j.1468-2982.2008.01770.x
5. Cal R, Bahmad FJr. Migraine associated with auditory-vestibular dysfunction. Braz J Otorhinolaryngol. 2008;74(4):606-12. doi: 10.1016/S1808-8694(15)30611-X

6. Liveing E. On megrim, sick-headache, and some allied disorders. London, UK: Churchill, 1873.

7. Kayan A, Hood JD. Neuro-otological manifestations of migraine. Brain. 1984;107(4):1123-42. doi:10.1093/brain/107.4.1123

8. Furman JM, Marcus DA, Balaban CD. Migrainous vertigo: development of a pathogenetic model and structured diagnostic interview. Curr Opin Neurol. 2003;16(1):5-13. doi:10.1097/00019052-200302000-00002

9. Neuhauser, H.K., Lempert, T. Vertigo: epidemiologic aspects. Semin Neurol. 2009;9(5):473-81. doi:10.1055/s-0029-1241043 
10. Brandt T, Strupp M. Migraine and vertigo: classification, clinical features, and special treatment considerations. Headache Currents. 2006;3(1):12-9. doi:10.1111/j.1743-5013.2006.00027.x

11. Geser R, Straumann D. Referral and final diagnoses of patients assessed in an academic vertigo center. Front Neurol. 2012;3:169. doi:10.3389/fneur.2012.00169

12. Neuhauser HK, Radtke A, Brevern M, Feldmann M, Lezius F, Ziese Tet al. Migrainous vertigo: prevalence and impact on quality of life. Neurology. 2006;67:1028. doi:10.1212/01.wnl.0000237539.09942.06

13. Neuhauser $\mathrm{H}$, Lempert T. Vertigo and dizziness related to migraine: a diagnostic challenge. Cephalalgia. 2004;24(2):83-91. doi:10.1111/j.1468-2982.2004.00662.x

14. Hsu LC, Wang SJ, Fuh JL. Prevalence and impact of migrainous vertigo in mid-life women: a community-based study. Cephalalgia. 2011;31(1):77-83. doi:10.1177/0333102410373152

15. Dieterich M, Brandt T. Episodic vertigo related to migraine (90 cases): vestibular migraine? J Neurol. 1999;246(10):883-92. doi:10.1007/s004150050478

16. Murdin L, Davies RA, Bronstein AM. Vertigo as a migraine trigger. Neurology. 2009;73(8):638-42. doi:10.1212/WNL.0b013e3181b38a04

17. Abu-Arafeh I, Russell G. Paroxysmal vertigo as a migraine equivalent in children: a population-based study. Cephalalgia. 1995;15(1):22-5. doi:10.1046/j.1468-2982.1995.1501022.x

18. Sargent, EW. The challenge of vestibular migraine. Curr Opin Otolaryngol Head Neck Surg. 2013;21(5):473-9. doi:10.1097/M00.0b013e3283648682

19. Balaban CD. Migraine, vertigo and migrainous vertigo: links between vestibular and pain mechanisms. J Vestib Res. 2011;21(6):315-21. doi:10.3233/VES-2011-0428

20. Schuerger RJ, Balaban CD. Organization of the coeruleo-vestibular pathway in rats, rabbits, and monkeys. Brain Res Brain Res Rev. 1999;30(2):189-217. doi:10.1016/S0165-0173(99)00015-6

21. Halberstadt AL, Balaban CD. Organization of projections from the raphe nuclei to the vestibular nuclei in rats. Neuroscience. 2003;120(2):573-94. doi:10.1016/S0306-4522(02)00952-1

22. Marano E, Marcelli V, Di Stasio E, Bonuso S, Vacca G, Manganelli F et al. Trigeminal stimulation elicits a peripheral vestibular imbalance in migraine patients. Headache. 2005;45(4):325-31. doi:10.1111/j.1526-4610.2005.05069.x

23. Shin JH, Kim YK, Kim HJ, Kim JS. Altered brain metabolism in vestibular migraine: comparison of interictal and ictal findings. Cephalalgia. 2014;34(1):58-67. doi:10.1177/0333102413498940

24. Russo A, Marcelli V, Esposito F, Corvino V, Marcuccio L, Giannone A et al. Abnormal thalamic function in patients with vestibular migraine. Neurology. 2014;82(23):2120-6. doi:10.1212/WNL.0000000000000496

25. Stolte B, Holle D, Naegel S, Diener HC, Obermann M. Vestibular migraine. Cephalalgia. 2014;35(3):262-70. doi:10.1177/0333102414535113

26. Bahmad FJr, DePalma SR, Merchant SN, Bezerra RL, Oliveira CA, Seidman CE et al. Locus for familial migrainous vertigo disease maps to chromosome 5q35. Ann Otol Rhinol Laryngol. 2009;118(9):670-6. doi:10.1177/000348940911800912

27. Lee H, Jen JC,Wang H, Chen Z, Mamsa H, Sabatti C et al. A genome-wide linkage scan of familial benign recurrent vertigo: linkage to 22q12 with evidence of heterogeneity. Hum Mol Genet. 2006;15(2):251-8. doi:10.1093/hmg/ddi441

28. International Headache Society. The International Classification of Headache Disorders, 3rd edition (beta version). Cephalalgia. 2013;33(9):629-808. doi:10.1177/0333102413485658

29. Furman JM, Marcus DA, Balaban CD. Vestibular igraine: clinical aspects and pathophysiology. Lancet Neurol. 2013;12(7):706-15. doi:10.1016/S1474-4422(13)70107-8
30. Cohen JM, Bigal ME, Newman LC. Migraine and vestibular symptoms: identifying clinical features that predict "vestibular migraine". Headache. 2011;51(9):1393-7. doi:10.1111/j.1526-4610.2011.01934.x

31. Strupp M, Versino M, Brandt T. Vestibular migraine. Handb Clin Neurol. 2010;97:755-71. doi:10.1016/S0072-9752(10)97062-0

32. Cutrer FM, Baloh RW. Migraine-associated dizziness. Headache. 1992;32(6):300-4. doi:10.1111/j.1526-4610.1992.hed3206300.x

33. Johnson GD. Medical management of migraine-related dizziness and vertigo. Laryngoscope. 1998;108(suppl S85):1-28. doi:10.1111/j.1526-4610.1992.hed3206300.x

34. Reploeg MD, Goebel JA. Migraine-associated dizziness: patient characteristics and management options. Otol Neurotol. 2002;23(3):364-71. doi:10.1097/00129492-200205000-00024

35. Lempert T, Neuhauser H. Epidemiology of vertigo, migraine and vestibular migraine. J Neurol. 2009;256(3):333-8. doi:10.1007/s00415-009-0149-2

36. Radtke A, Brevern M, Neuhauser H, Hottenrott T, Lempert T. Vestibular migraine: long-term follow-up of clinical symptoms and vestibulo-cochlear findings. Neurology. 2012;79(15):1607-14. doi:10.1212/WNL.0b013e31826e264f

37. Lempert, T. Vestibular migraine. Semin Neurol. 2013;33(3):212-8. doi:10.1055/s-0033-1354596

38. Vitkovic J, Paine M, Rance G. Neuro-otological findings in patients with migraine- and nonmigraine-related dizziness. Audiol Neurootol. 2008;13(2):113-22. doi:10.1159/000111783

39. Brevern M, Zeise D, Neuhauser H, Clarke AH, Lempert T. Acute migrainous vertigo: clinical and oculographic findings. Brain. 2005;128(2):365-74. doi:10.1093/brain/awh351

40. Ménière P. Pathologie auriculaire: memoires sur une lésion de l'oreille interne donnant lieu à des symptoms de congestion cérébrale apoplectiforme. Gaz Med Paris. 1861;16:597-601.

41. Parker W. Menière's disease. Etiologic considerations. Arch Otolaryngol Head Neck Surg. 1995;121(4):377-82. doi:10.1001/archotol.1995.01890040005001

42. Radtke A, Lempert T, Gresty MA, Brookes GB, Bronstein AM, Neuhauser H. et al. Migraine and Ménière's disease: is there a link? Neurology. 2002;59(11):1700-4. doi:10.1212/01.WNL.0000036903.22461.39

43. Griev, SM, Obholzer R, Malitz N, Gibson WP, Parker GD. Imaging of endolymphatic hydrops in Meniere's disease at 1.5 T using phase-sensitive inversion recovery: (1) demonstration of feasibility and (2) overcoming the limitations of variable gadolinium absorption. Eur J Radiol. 81(2):331-8. doi:10.1016/j.ejrad.2011.01.073

44. Gürkov R, Kantner C, Strupp M, Flatz W, Krause E, Ertl Wagner B. Endolymphatic hydrops in patients with vestibular migraine and auditory symptoms. Eur Arch Otorhinolaryngol. 2014;271(10):2661-7. doi:10.1007/s00405-013-2751-2

45. Nakada T, Yoshida T, Suga K, Kato M, Otake H, Kato Ket al. Endolymphatic space size in patients with vestibular migraine and Ménière's disease. J Neurol. 2014;261(11):2079-84. doi:10.1007/s00415-014-7458-9

46. Lee SH, Kim JS. Benign paroxysmal positional vertigo. J Clin Neurol. 2010;6(2):51-63. doi:10.3988/jcn.2010.6.2.51

47. Brevern M, Radtke A, Clarke AH and Lempert T. Migrainous vertigo presenting as episodic positional vertigo. Neurology. 2004;62(3):469-72. doi:10.1212/01.WNL.0000106949.55346.CD

48. Baloh RW. Vertebrobasilar insufficiency and stroke. Otolaryngol Head Neck Surg. 1995;112(1):114-7. doi:10.1016/S0194-5998(95)70309-8

49. Maione A. Migraine-related vertigo: diagnostic criteria and prophylactic treatment. Laryngoscope. 2006;116(10):1782-86. doi:10.1097/01.mlg.0000231302.77922.c5

50. Neuhauser H, Radtke A, Brevern M, Lempert T. Zolmitriptan for treatment of migrainous vertigo: a pilot randomized 
placebo-controlled trial. Neurology. 2003;60(5):882-3. doi:10.1212/01.WNL.0000049476.40047.A3

51. Lepcha A, Amalanathan S, Augustine AM, Tyagi AK, Balraj A. Flunarizine in the prophylaxis of migrainous vertigo: a randomized controlled trial. Eur Arch Otorhinolaryngol. 2014;271(11):2931-6. doi:10.1007/s00405-013-2786-4

52. Taghdiri F, Togha M, Razeghi Jahromi S, Refaeian F. Cinnarizine for the prophylaxis of migraine associated vertigo: a retrospective study. SpringerPlus. 2014;3(1):231. doi:10.1186/2193-1801-3-231

53. BisdorffAR. Treatment of migraine related vertigo with lamotrigine an obsevational study. Bull Soc Sci Med Grand Duche Luxemb. 2004;(2):103-8.

54. Baier B, Winkenwerder E, Dieterich M. "Vestibular migraine": effects of prophylactic therapy with various drugs: a retrospective study. J Neurol. 2009;256(3):436-42. doi:10.1007/s00415-009-0111-3

55. Obermann M, Strupp M. Current treatment options in vestibular migraine. Front Neurol. 2014;5:257. doi:10.3389/fneur.2014.00257
56. Mikulec AA, Faraji F, Kinsella LJ. Evaluation of the efficacy of caffeine cessation, nortriptyline, and topiramate therapy in vestibular migraine and complex dizziness of unknown etiology. Am J Otolaryngol. 2012;33(1):121-7. doi:10.1016/j.amjoto.2011.04.010

57. Vitkovic J, Winoto A, Rance G, Dowell R, Paine M. Vestibular rehabilitation outcomes in patients with and without vestibular migraine. J Neurol. 2013;260(12):3039-48. doi:10.1007/s00415-013-7116-7

58. Whitney SL, Wrisley DM, Brown KE, Furman JM. Physical therapy for migraine related vestibulopathy and vestibular dysfunction with history of migraine. Laryngoscope. 2000;110(9):1528-34. doi:10.1097/00005537-200009000-00022

59. Wrisley DM, Whitney SL, Furman JM. Vestibular rehabilitation outcomes in patients with a history of migraine. Otol Neurotol. 2002;23(4):483-7. doi:10.1097/00129492-200207000-00016 